\title{
Surface Roughness Mediated Adhesion Forces between Borosilicate Glass and Gram-Positive Bacteria
}

\author{
Emily Preedy, ${ }^{\dagger}$ Stefano Perni, ${ }^{\dagger, \S}$ Damijan Nipic,, Klemen Bohinc, $^{\perp}$ and Polina Prokopovich ${ }^{*}, \dagger, \S$ \\ ${ }^{\dagger}$ Cardiff School of Pharmacy and Pharmaceutical Science and ${ }^{\ddagger}$ Cardiff School of Engineering, Cardiff University, Cardiff CF10 3XQ \\ UK \\ ${ }^{\S}$ Department of Biological Engineering, Massachusetts Institute of Technology, Cambridge, Massachusetts 02139, United States \\ "Department of Biology, Biotechnical Faculty, and ${ }^{\perp}$ Faculty of Health Science, University of Ljubljana, 1000 Ljubljana, Slovenia
}

\section{Supporting Information}

ABSTRACT: It is well-known that a number of surface characteristics affect the extent of adhesion between two adjacent materials. One of such parameters is the surface roughness as surface asperities at the nanoscale level govern the overall adhesive forces. For example, the extent of bacterial adhesion is determined by the surface topography; also, once a bacteria colonizes a surface, proliferation of that species will take place and a biofilm may form, increasing the resistance of bacterial cells to removal. In this study, borosilicate glass was employed with varying surface roughness and coated with
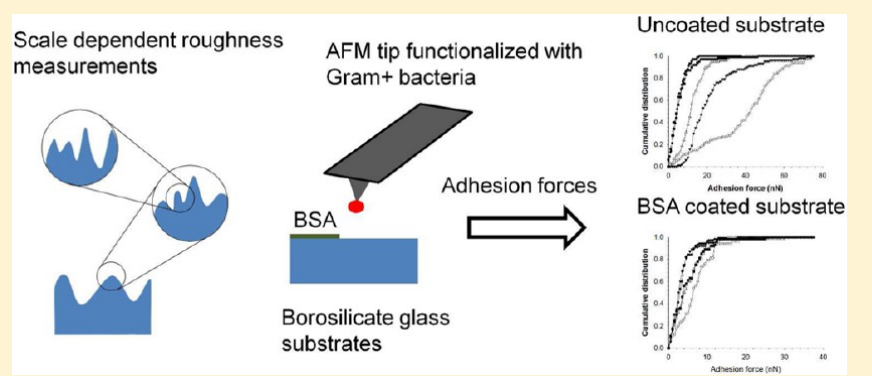
bovine serum albumin (BSA) in order to replicate the protein layer that covers orthopedic devices on implantation. As roughness is a scale-dependent process, relevant scan areas were analyzed using atomic force microscope (AFM) to determine $R_{\mathrm{a}}$; furthermore, appropriate bacterial species were attached to the tip to measure the adhesion forces between cells and substrates. The bacterial species chosen (Staphylococci and Streptococci) are common pathogens associated with a number of implant related infections that are detrimental to the biomedical devices and patients. Correlation between adhesion forces and surface roughness $\left(R_{\mathrm{a}}\right)$ was generally better when the surface roughness was measured through scanned areas with size $(2 \times 2 \mu \mathrm{m})$ comparable to bacteria cells. Furthermore, the BSA coating altered the surface roughness without correlation with the initial values of such parameter; therefore, better correlations were found between adhesion forces and BSA-coated surfaces when actual surface roughness was used instead of the initial (nominal) values. It was also found that BSA induced a more hydrophilic and electron donor characteristic to the surfaces; in agreement with increasing adhesion forces of hydrophilic bacteria (as determined through microbial adhesion to solvents test) on BSA-coated substrates.

\section{INTRODUCTION}

Biofilms are defined as a layer or layers of cells adhered to a substratum which are generally embedded in a organic biological matrix, i.e., extracellular polymeric substances (EPS). ${ }^{1-4}$ It is due to biofilm formation that many bacteria survive in highly diverse and adverse environments as a result of the polymicrobial ecosystem. Not surprisingly, biofilms have formed on a variety of surfaces and are not only restricted to attachment at a solid-liquid interface but have been observed at solid-air and liquid-liquid interfaces, ${ }^{1,5,8}$ with some having beneficial results as well as detrimental; for example, in industry biofilms are used successfully to separate coal particles from mineral matter. 9,10

On the other hand, biofilms have been known to cause biofouling reducing mass and heat transfer and effectively increasing corrosion; 6,11 also from a medical point of view, biofilm colonized implanted medical devices often lead to implant failure. ${ }^{8}$ Furthermore, the food industry has had a major interest in biofilms as a result of their resistance to cleaning and disinfection because spoilage and pathogenic bacteria pose a risk to public health and product quality. ${ }^{11-13}$
Also in the paper industry, biofilms can trap certain particles, calcium carbonate, and cellulose fibers, causing problems with the formation of a thick slimy deposit which clogs wires resulting in sheet breakages and reduction in paper quality because of holes, odors, and even discoloration. ${ }^{14}$

The formation of biofilms is a complex multistep process which is dependent on a number of variables such as the type of microorganism, the surface of attachment, and the surrounding environment. ${ }^{5}$ Initially, microorganisms attachment to an abiotic surface occurs mainly through hydrophobic interactions; yet adhesion in living tissue takes place through specific molecular mechanisms such as ligands. In the first stage of attachment, cells are reversibly bound to a surface; this step is governed by the repulsive energy barrier, when occurring and resulting from the overlap of the negatively charged substratum surface produced by the electrical double layer formed in an aqueous environment. ${ }^{7}$ Nevertheless, many bacteria can

Received: May 8, 2014

Revised: July 9, 2014

Published: July 14, 2014 
overcome the repulsive energy barrier by effectively penetrating this obstacle using features such as nanofibers, for example flagella, while others produce EPS to bridge the cell to the substratum surface effectively forming the conditioning layer. ${ }^{5,7,10}$ As well as these effective bridging actions, these crucial initial stages of attachment are mediated by a number of other interactions, namely van der Waals attractive forces, electrostatic repulsive forces, and surface hydrophobicity. ${ }^{15}$ The predominance of these forces is dependent on the distance between the microorganism and the surface, usually at distances greater than $50 \mathrm{~nm}$ van der Waals (vdW) forces are the main factor, while at closer distances $(10-20 \mathrm{~nm})$ a combination of both vdW and electrostatic interactions controls cell adhesion. ${ }^{5}$

A conditioning film is often provided by body fluids; this has also been noted to play a role in biofilm formation; for instance, in dentistry, teeth can be coated by a protein layer made of albumin, lysosomes, glycoproteins, lipids, and gingival crevice fluid, ${ }^{10}$ allowing for anchoring points to which flagella can attach. The conditioning film may be very complex and often results in chemical modification of the substratum surface which effectively influences the rate and extent of attachment of the bacteria; ${ }^{5}$ this results from the conditioning film effectively creating a foundation base that masks the surface features. The adhesion process on a coated substratum is, therefore, dominated by this conditioning film. ${ }^{5}$

Certain parameters such as the surface hydrophobicity/ hydrophilicity, ${ }^{15,16}$ topography, and roughness ${ }^{17-19}$ are known to have a dominating role in the extent of adhesion that is essential for the biofilm growth phase to be successful. At large and intermediate separation distances between cell and substrate, macroscopic cell surface properties (such as surface free energy, surface charge, and hydrophobicity/hydrophilicity) control the initial attachment, while at small separation distances (below $5 \mathrm{~nm}$ ) microscopic molecular short-range interactions mediate bacterial adhesion. ${ }^{20,21}$ It has been hypothesized $^{20,22}$ that asperities or peaks and other surface structures on both interacting surfaces may result in a decrease in the total interacting energy as well as the height of the energy barrier that the microbial cell must overcome before adhering to the substratum surface; hence, there may be a greater rate of adhesion on rougher surfaces ${ }^{17}$ with a positive correlation with the rate of colonization, especially in oral implants. ${ }^{17,18,23}$ Additionally, surface roughness is a scale-dependent process, i.e., results from undulations and imperfections on the surface of a material in relation to the observed or scanned area; therefore, average surface roughness $\left(R_{\mathrm{a}}\right)$ or root-mean-squared (RMS) values may be different at the macroscale compared to the microscale and even at the nanoscale. ${ }^{24,25}$

Atomic force microscopy (AFM) is a technique that employs the deflection of a cantilever in proximity of a surface to determine the topography and/or the interfacial forces between two surfaces; cantilevers have also been functionalized with cells to quantify forces acting between surfaces and bacteria. ${ }^{26}$

The aim of this study was to investigate the role of surface roughness, in relation to a scanned area comparable with the size of bacteria, on the forces of adhesion between the material and cells. Borosilicate glasses, uncoated and coated with bovine serum albumin (BSA), of different micro- and nanoscale roughness have been used in this work against various bacterial species-Staphylococcus epidermidis, Staphylcoccus aureus, and Streptococcus mutans-employing AFM to analyze the adhesive forces associated with these bacterial species and substrates. These bacteria are some of the common causes of infections associated with medical devices; specifically Staphylococci in orthopedic implanted devices (where borosilicate glass mimics orthopedic materials), while $S$. mutans in oral cavity related applications (where glass has been used to coat titanium dental implants ${ }^{27}$ ).

\section{MATERIALS AND METHODS}

Borosilicate Glass. Samples of borosilicate glass (size $2 \times 2 \mathrm{~cm}$ with thickness of $2 \mathrm{~mm}$ ) were cut from TEMPAX sheet glass obtained from Schott under constant temperature of $510^{\circ} \mathrm{C}$, and the surfaces of glass pieces were fused using a gas burner. Increasing roughness of the glass was achieved by grinding to specific gradation using abrasive particles of varying sizes. After polishing the edges of the glass plates were then fused again; untreated glass samples were used as a control. In total, five glass materials were employed: A - control (untreated), $\mathrm{B}, \mathrm{C}, \mathrm{D}$, and $\mathrm{E}$ of increasing roughness.

Macroscale Roughness Measurements. The macro scale roughness of the sample was determined using a mechanical profilometer (Talysurf Series 2, Taylor-Hobson Ltd., Leicester, U.K.).

Bacteria and AFM Tip Functionalization. Staphylococcus epidermidis RP62 and ATCC 12228, Staphylococcus aureus ATCC 25923, and Streptococcus mutans NCTC 10449 were cultured statically in brain heart infusion (BHI, Oxoid, UK) broth overnight at $37^{\circ} \mathrm{C}$, before placing a $100 \mu \mathrm{L}$ drop of bacteria suspension onto a previously poly(L-lysine) $(0.1 \% \mathrm{w} / \mathrm{v}$ solution, Sigma, UK) coated AFM tips. The drop was left for $30 \mathrm{~min}$ before attaching the functionalized tip to the liquid head of the AFM. Each functionalized tip was used only once.

Bovine Serum Albumin Coating (BSA). A $1 \% \mathrm{w} / \mathrm{v}$ solution of bovine serum albumin (BSA) (Sigma-Aldrich, UK) was used to coat the glass samples. Samples were immersed in a $10 \mathrm{~mL}$ solution for 30 $\mathrm{min}$ at room temperature prior to analysis.

Scanning Electron Microscopy (SEM). Bacterial functionalized AFM tips were fixed with $2 \%$ glutaraldehyde for $2 \mathrm{~h}$ and then dehydrated in alcohol solutions of progressive concentrations: 70, 90, and $100 \%$. Each tip was gold coated using a sputter coater (Agar Model 109A, Standsted, Essex, UK), with a mixture of gold and palladium ( $80 \%$ and $20 \%$, respectively) in argon gas; all tips were exposed for $15 \mathrm{~s}$, and this was repeated four times to achieve an even coating. Once coated, the tips were transferred to the scanning electron microscope (SEM) sample holder and imaged (XB1540, Carl Zeiss, Germany).

Atomic Force Microscopy (AFM). An atomic force microscope (AFM) (XE-100 Advanced Scanning Probe Microscope, Park Systems, Korea) was used to analyze the surface roughness, surface topography, and adhesion forces.

Surface Topography Analyses. Contact mode was employed for all AFM analysis; the microscale roughness was measured using scanned areas of $10 \times 10 \mu \mathrm{m}$, whereas areas of $2 \times 2 \mu \mathrm{m}$ were scanned for the nanoscale roughness. Images were obtained using a contact rectangular tip, CSG30 (NT-MDT, The Netherlands), with reflective Au side, a spring constant of $3.3 \mathrm{~N} / \mathrm{m}$, tip height of $14 \mu \mathrm{m}$, and a tip curvature radius of $10 \mathrm{~nm}$; each tip was calibrated using the Sader method. ${ }^{28}$ The scan parameters used were as follows: resolution at $1024 \times 1024$; scan rate between 0.8 and $1.0 \mathrm{~Hz}$ and applied load of 10 $\mathrm{nN}$. For each glass sample, six replicate scans were made and the average surface roughness $\left(R_{\mathrm{a}}\right)$ determined.

Adhesion Force Measurements. All adhesive force measurements were conducted in an open liquid cell made of polychlorofluoroethylene, PCTFE (Park Systems, Korea), using phosphate buffer solution (PBS) as the aqueous environment. In order to gain comprehensive data for the adhesive interactions of the given samples, the surface mapping feature of the AFM was employed with a tip functionalized with the chosen bacteria species. Using $2 \times 2 \mu \mathrm{m}$ scan size, 100 curves per area and three areas were scanned on separate occasions on each sample using three functionalized cantilever with three independent cultures of the same bacterium; therefore, at least 300 curves were collected per glass sample and bacteria as well as control experiments. 
Table 1. Average Roughness $\left(R_{\mathrm{a}}\right)$ Measurements of Each Glass Sample (A-E) at Varying Scales before and after BSA Coating

\begin{tabular}{|c|c|c|c|c|c|}
\hline \multirow[b]{2}{*}{ roughness scale $(\mathrm{nm})$} & \multicolumn{5}{|c|}{ glass samples } \\
\hline & A & B & $\mathrm{C}$ & $\mathrm{D}$ & $\mathrm{E}$ \\
\hline macro & 100 & 500 & 1000 & 2500 & 6000 \\
\hline micro & $0.250 \pm 0.12$ & $20.00 \pm 0.05$ & $34.6 \pm 0.15$ & $56.10 \pm 0.12$ & $94.40 \pm 0.54$ \\
\hline nano & $0.259 \pm 0.04$ & $21.90 \pm 7.65$ & $37.0 \pm 16.29$ & $56.30 \pm 10.82$ & $62.15 \pm 9.04$ \\
\hline micro after BSA coating & $1.54 \pm 0.19$ & $52.62 \pm 0.03$ & $81.87 \pm 0.02$ & $103.63 \pm 0.02$ & $145.88 \pm 0.02$ \\
\hline nano after BSA coating & $1.35 \pm 0.57$ & $3.04 \pm 0.93$ & $4.78 \pm 1.22$ & $2.93 \pm 0.68$ & $4.25 \pm 1.42$ \\
\hline
\end{tabular}
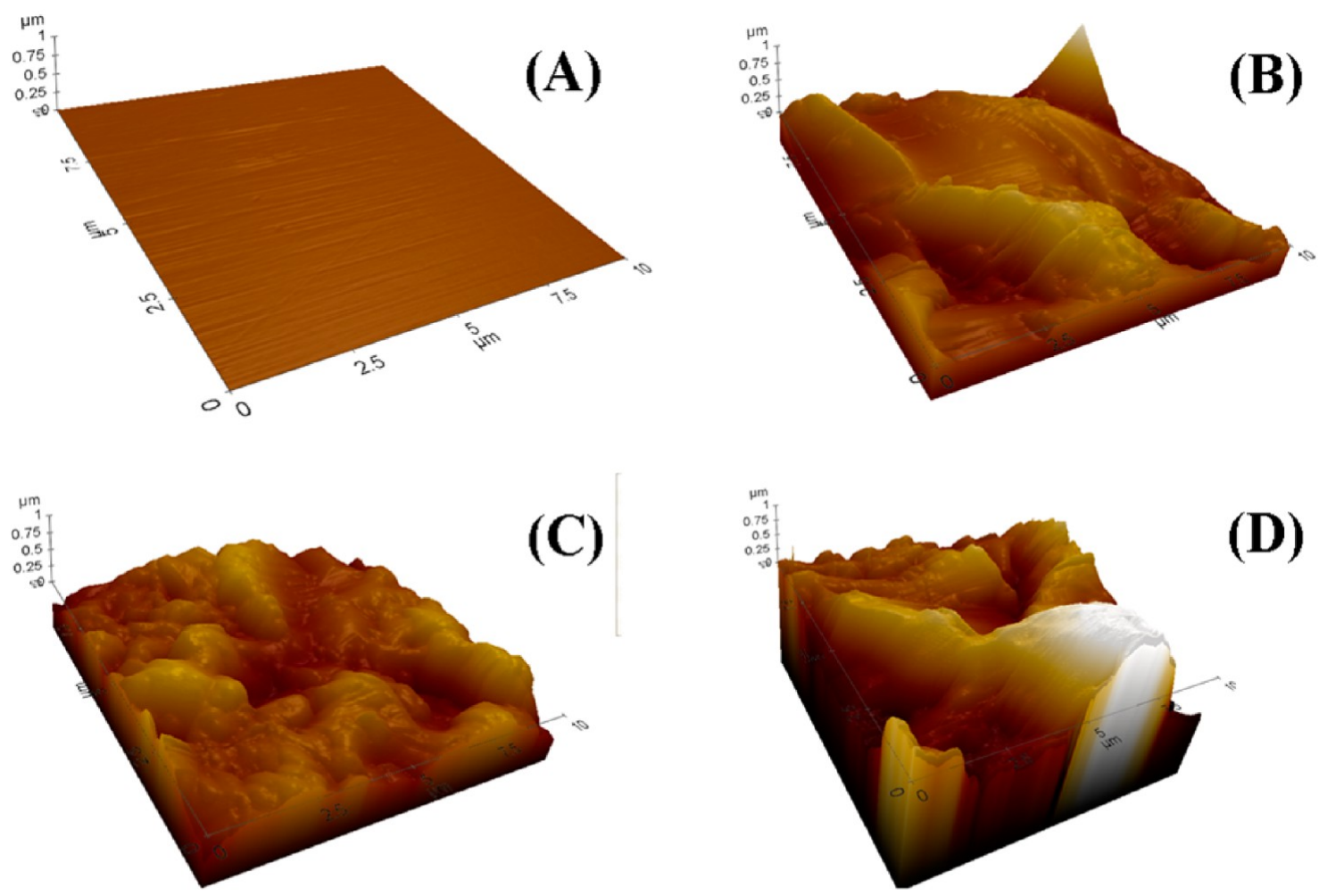

(D)

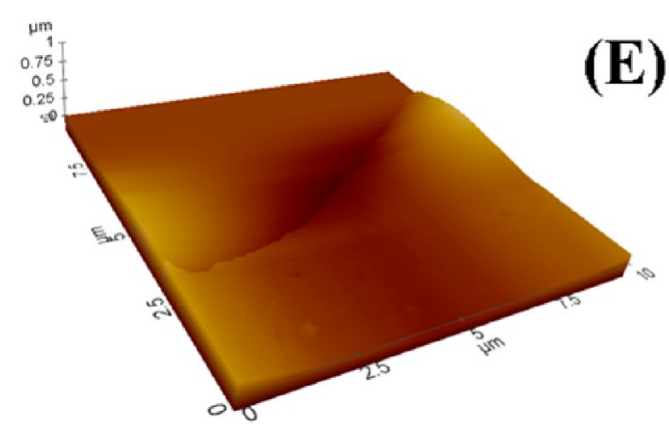

Figure 1. Microscale images of each (A to E) bare glass samples.

Retraction of the bacterial probe from a composite surface with and without BSA was done without delay $(0 \mathrm{~s})$ in order to avoid possible bond strengthening.

Scanning electron micrographs were taken at the end of the experiments to confirm that no visual damage occurred to the bacterial probe as results of the measurements; for this study no force-distance curves had to be discarded due to a damaged probe.

Microbial Adhesion to Solvents (MATS). MATS protocol, a two phases partitioning assay, was developed by Bellon-Fontaine et al. ${ }^{29}$ to determine physical-chemical properties of bacterial surfaces. The cell suspensions, prepared as previously described, were centrifuged for 10 min at $6037 \mathrm{~g}$ (HERMLE centrifuge Z-383 K, LabPlant, Huddersfields,
U.K.) at $4{ }^{\circ} \mathrm{C}$. Cells were washed with a $\mathrm{NaCl}$ solution $(0.15 \mathrm{M})$ and centrifuged three more times. The final suspension was diluted with the same $\mathrm{NaCl}$ solution to a final cell concentration of about $10^{8}$ CFU/mL. $2.0 \mathrm{~mL}$ of this cell suspension and $0.5 \mathrm{~mL}$ of one of the solvents (chloroform, hexadecane, ethyl acetate and decane (Sigma, $\mathrm{UK})$ ) were vortexed together for $1 \mathrm{~min}$. The emulsion was left to stand for $15 \mathrm{~min}$ to allow the two phases to separate.

The absorbance of the aqueous phase was evaluated at $450 \mathrm{~nm}$ with a spectrophotometer (UV-1201, Shimadzu (UK), Milton Keynes). The affinity of the bacterial species for each solvent was determined using the equation 

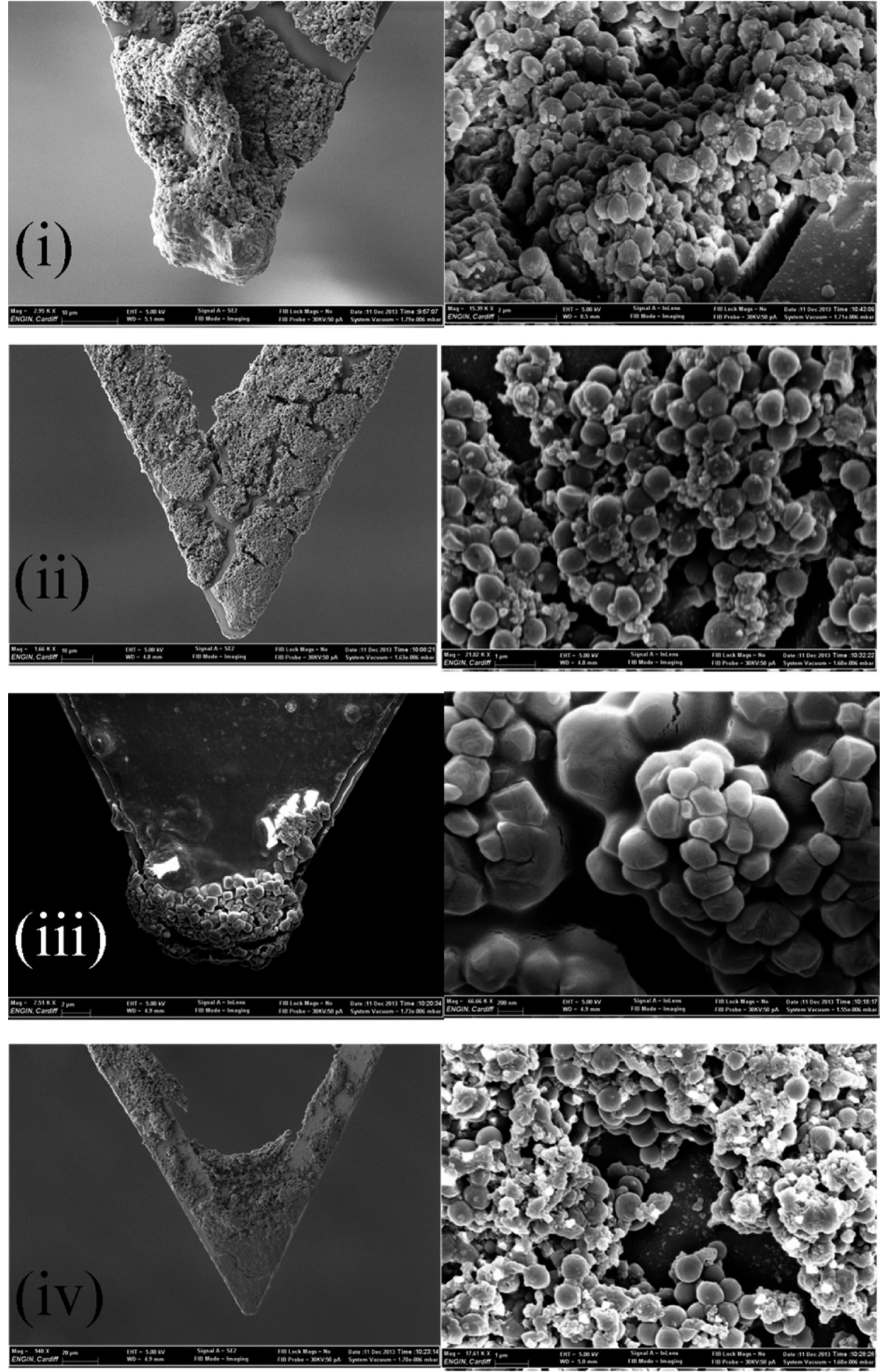

Figure 2. SEM images demonstrating bacterial attachement on an AFM tip: (i) S. epidermidis RP62a, (ii) S. epidermidis 12228, (iii) S. aureus, and (iv) S. mutans.

$$
\% \text { affinity }=100 \times\left(1-\frac{A}{A_{0}}\right)
$$

where $A_{0}$ is the absorbance at $450 \mathrm{~nm}$ of the suspension before mixing and $A$ is the absorbance of the suspension after mixing with one of the solvents. This protocol was carried out on cells that originated from four independent cultures, and the results are presented as mean values \pm standard deviation.

Contact Angles and Surface Energy. The surface energy components of the samples were determined using the thermodynamic approach, based on contact angle measurements. ${ }^{32}$ Three probe liquids, with different polarities, were used: distilled water, glycerol, 
Table 2. Contact Angles of Water $\left(\vartheta_{\mathrm{w}}\right)$, Glycerol $\left(\boldsymbol{\vartheta}_{\mathrm{g}}\right)$, Hexadecane $\left(\boldsymbol{\vartheta}_{\mathrm{h}}\right)$ on Borosilicate Glass Samples $($ Mean \pm Standard Deviation) and Surface Energy Parameters

\begin{tabular}{ccccccccc} 
sample & $\vartheta_{\mathrm{w}}$ & $\vartheta_{\mathrm{g}}$ & $\vartheta_{\mathrm{h}}$ & $\gamma_{\mathrm{S}}^{\mathrm{LW}}\left(\mathrm{mJ} / \mathrm{m}^{2}\right)$ & $\gamma_{\mathrm{S}}^{+}\left(\mathrm{mJ} / \mathrm{m}^{2}\right)$ & $\gamma_{\mathrm{S}}^{-}\left(\mathrm{mJ} / \mathrm{m}^{2}\right)$ & $\gamma_{\mathrm{S}}^{\mathrm{AB}}\left(\mathrm{mJ} / \mathrm{m}^{2}\right)$ & $\gamma_{\mathrm{S}}^{\mathrm{TOT}}\left(\mathrm{mJ} / \mathrm{m}^{2}\right)$ \\
A & $27 \pm 4$ & $59 \pm 7$ & $4 \pm 1$ & 27.2 & 0.1 & 72.4 & 5.4 & 32.5 \\
$\mathrm{~B}$ & $47 \pm 5$ & $65 \pm 5$ & $4 \pm 1$ & 27.2 & 0.1 & 49.0 & 4.4 & 31.6 \\
$\mathrm{C}$ & $50 \pm 2$ & $68 \pm 7$ & $4 \pm 1$ & 27.2 & 0.0 & 48.0 & 1.4 & 28.5 \\
D & $44 \pm 3$ & $65 \pm 4$ & $4 \pm 1$ & 27.2 & 0.0 & 55.0 & 2.6 & 29.7 \\
E & $43 \pm 5$ & $62 \pm 3$ & $4 \pm 1$ & 27.2 & 0.2 & 52.0 & 6.9 & 34.1 \\
\hline
\end{tabular}

Table 3. Contact Angles of Water $\left(\boldsymbol{\vartheta}_{w}\right)$, Glycerol $\left(\boldsymbol{\vartheta}_{g}\right)$, Hexadecane $\left(\boldsymbol{\vartheta}_{h}\right)$ on BSA-Coated Borosilicate Glass Samples $($ Mean \pm Standard Deviation) and Surface Energy Parameters

\begin{tabular}{|c|c|c|c|c|c|c|c|c|}
\hline sample & $\vartheta_{w}$ & $\vartheta_{\mathrm{g}}$ & $\vartheta_{\mathrm{h}}$ & $\gamma_{\mathrm{S}}^{\mathrm{LW}}\left(\mathrm{mJ} / \mathrm{m}^{2}\right)$ & $\gamma_{S}^{+}\left(\mathrm{mJ} / \mathrm{m}^{2}\right)$ & $\gamma_{\mathrm{S}}^{-}\left(\mathrm{mJ} / \mathrm{m}^{2}\right)$ & $\gamma_{\mathrm{S}}^{\mathrm{AB}}\left(\mathrm{mJ} / \mathrm{m}^{2}\right)$ & $\gamma_{\mathrm{S}}^{\mathrm{TOT}}\left(\mathrm{mJ} / \mathrm{m}^{2}\right)$ \\
\hline A & $4 \pm 1$ & $56 \pm 5$ & $4 \pm 1$ & 27.2 & 0.1 & 86.0 & 5.9 & 33.0 \\
\hline B & $3 \pm 2$ & $51 \pm 4$ & $4 \pm 1$ & 27.2 & 0.5 & 79.0 & 4.4 & 31.5 \\
\hline $\mathrm{C}$ & $4 \pm 1$ & $56 \pm 4$ & $4 \pm 1$ & 27.2 & 0.1 & 87.0 & 4.4 & 31.5 \\
\hline $\mathrm{D}$ & $4 \pm 1$ & $56 \pm 3$ & $4 \pm 1$ & 27.2 & 0.1 & 85.8 & 5.9 & 33.0 \\
\hline $\mathrm{E}$ & $3 \pm 1$ & $56 \pm 8$ & $4 \pm 1$ & 27.2 & 0.1 & 86.0 & 5.9 & 33.0 \\
\hline
\end{tabular}

and hexadecane (Sigma-Aldrich, UK). A drop of $5 \mu \mathrm{L}$ of each liquid was deposited on the sample and images were immediately recorded. Contact angles at both the right and the left side were measured using Image (NIH). The mean value of 10 readings was calculated for each sample and for each liquid.

\section{RESULTS}

Surface Topography. The roughness measurements at the macroscale level, measured using the profilometer, are shown in Table 1, demonstrating that glass sample A was the smoothest with an increase in roughness up to glass sample $\mathrm{E}$, with $R_{\mathrm{a}}$ values of 100 and $6000 \mathrm{~nm}$, respectively.

All borosilicate glass samples were imaged to reveal the topography of their bare surface at the microscale level (Figure 1) using a $10 \times 10 \mu \mathrm{m}$ scan area and at the nanoscale level (see Supporting Information), $2 \times 2 \mu \mathrm{m}$ scan area. Samples were imaged again once coated with BSA (see Supporting Information). From these images the average roughness $\left(R_{\mathrm{a}}\right)$ measurements were gained and are presented in Table 1 .

At the microscale level glass, sample A was the smoothest $\left(R_{\mathrm{a}}\right.$ $=0.250 \mathrm{~nm}$ ); the $R_{\mathrm{a}}$ measurements gradually increased to the roughest sample, glass sample E, showing a $R_{\mathrm{a}}$ value of $94.4 \mathrm{~nm}$. It can be seen that there is an obvious correlation between surface images (Figure 1) and $R_{\mathrm{a}}$ values (Table 1 ), both demonstrating a roughness pattern glass $\mathrm{A}<$ glass $\mathrm{B}<$ glass $\mathrm{C}<$ glass $\mathrm{D}<$ glass $\mathrm{E}$. Similar observations could be made on the BSA-coated glass samples at microscale level, demonstrating the same pattern in roughness of $\mathrm{A}<\mathrm{B}<\mathrm{C}<\mathrm{D}<\mathrm{E}$; moreover, Table 1 demonstrated glass $\mathrm{A}$ was still the smoothest with $R_{\mathrm{a}}$ of $1.54 \mathrm{~nm}$, while glass $\mathrm{E}$ was the roughest at $R_{\mathrm{a}}$ of $145.88 \mathrm{~nm}$.

At the nanoscale level the pattern in roughness of sample $\mathrm{A}<$ $\mathrm{B}<\mathrm{C}<\mathrm{D}<\mathrm{E}$ was maintained for the clean samples, but $R_{\mathrm{a}}$ values were closer to their corresponding microscale values for the smooth sample. After BSA coating the pattern of surface roughness was altered (Table 1 ) as sample $C$ was rougher than $\mathrm{D}$ and $\mathrm{E}$.

AFM Tip Functionalization. In order to observe the positive functionalization of the AFM tips with bacteria, SEM was employed (Figure 2). It is clear from these images that functionalization of the tips was successful as cells were clustered on the AFM tip for each species of bacteria.

Contact Angles and Surface Energy Parameters. The contact angles for all three liquids on each glass sample are shown in Table 2. For water, the contact angle was lowest on glass sample A and almost half the value as glass samples B-E that had contact angles ranging between $43^{\circ}$ and $50^{\circ}$. The contact angles of glycerol demonstrated a slight increase from $58^{\circ}$ for glass sample $A$, with the other samples in the range of $61^{\circ}-67^{\circ}$. There was no change in the contact angle for hexadecane on any of the glass samples as this measurement remained at $4^{\circ}$. Contact angle measurements were also obtained for all glass samples coated with BSA, and the results are shown in Table 3; there was a difference in contact angles of water that ranged between $3^{\circ}$ and $5^{\circ}$ after BSA was applied. No changes were noticed for the contact angles of glycerol, and the same can be said regarding the measurements using hexadecane. The contact angles were used to calculate the surface energy parameters of the samples that are given in Table 2 for uncoated glass samples and in Table 3 for all BSAcoated glass. Overall, there was little difference in the electrondonor and electron-acceptor parameters $\left(\gamma^{\mathrm{AB}}\right)$, with a variation of a few $\mathrm{mJ} / \mathrm{m}^{2}$. Also, the Lifshitz-van der Waals surface free energy component $\left(\gamma^{\mathrm{LW}}\right)$ remained consistent throughout the glass samples at $27.2 \mathrm{~mJ} / \mathrm{m}^{2}$. Because of these small variations, it is obvious that the total surface free energies for all untreated bare glass samples had little difference and was in the range $29-34 \mathrm{~mJ} / \mathrm{m}^{2}$. Similarly, once the BSA coating was applied to each glass sample, the Lifshitz-van der Waals surface energy component remained the same as previously stated for the bare glass sample at $27.2 \mathrm{~mJ} / \mathrm{m}^{2}$. There was a slight increase in the electron-donor and electron-acceptor parameter when compared to the bare glass; however, there was no significant change between samples with the range increasing slightly to 4.4-5.9 $\mathrm{mJ} / \mathrm{m}^{2}$. Also, these calculations have shown a more consistent total surface free energy over all samples ranging from 31 to $33 \mathrm{~mJ} / \mathrm{m}^{2}$.

Microbial Adhesion to Solvent (MATS). The results of the MATS analysis are given in Figure 3 and demonstrated that S. epidermidis RP62a had the highest affinity to both nonpolar solvents, i.e., hexadecane and decane (around 64\%); S. epidermidis ATCC12228 also had high affinity for these nonpolar solvents with values of $52 \%$ and $64 \%$ for hexadecane and decane, respectively. From this, it could be deduced that both $S$. epidermidis strains were more hydrophobic compared to the other bacterial strains ( $S$. aureus and $S$. mutans), with $S$. aureus having a relative affinity at around $40 \%$ for hexadecane and $48 \%$ for decane, whereas $S$. mutans had the lowest affinity 


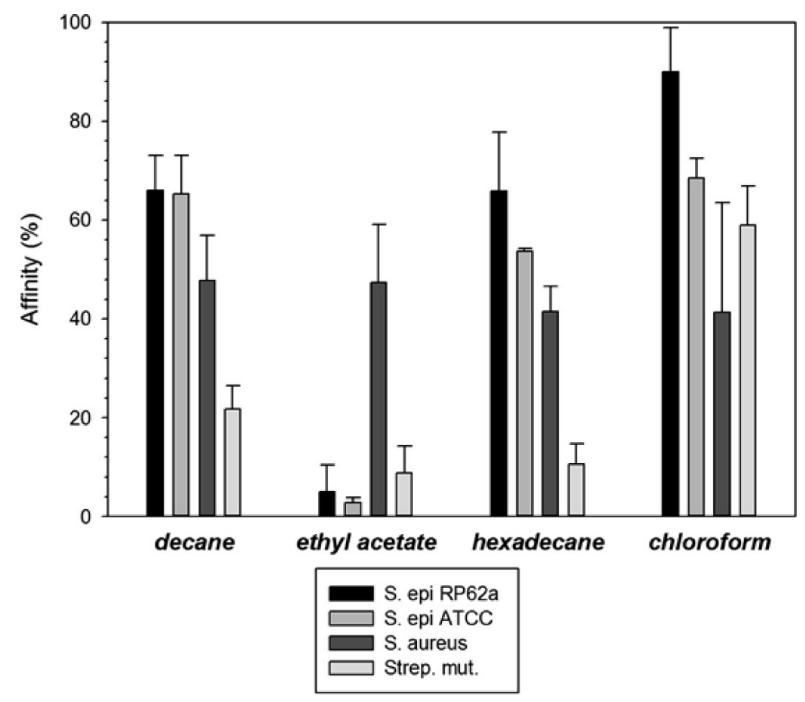

Figure 3. Affinity toward solvents of bacteria (microbial adhesion to solvents - MATS).

for both nonpolar solvents at around $8 \%$ for hexadecane and $20 \%$ for decane, suggesting hydrophilic properties.

It is obvious that $S$. epidermidis RP62a demonstrated the greatest affinity toward chloroform (92\%), suggesting that $S$. epidermidis RP62a had affinity toward electron acceptor materials, while the markedly lower affinity (4\%) for ethyl acetate indicating low attraction to electron donor surfaces. This is also the case for S. epidermidis ATCC12228; however, S. aureus had a strong affinity for ethyl acetate (electron donor) (48\%) and for chloroform (40\%); therefore, this bacterium had a moderate attraction to either electron donor or acceptor materials. Instead, $S$. mutans had a relatively high affinity for chloroform (60\%) and low for ethyl acetate, demonstrating this bacterium has high affinity toward electron acceptor materials.

Adhesion Force Measurements. Cumulative distribution of the adhesion forces measured for each bacterium on all substrates are shown in Figures 4 and 5. Almost in all cases these distributions did not appear to follow a Gaussian profile; therefore, median values were extracted in order to make comparisons (see tables in Supporting Information).

It was observed that $S$. mutans had the lowest adhesion force regardless of the roughness on uncoated glass surfaces in PBS (Figure 4). However, there was not a great difference in adhesion forces among $S$. epidermidis RP62a, S. epidermidis ATCC12228, and $S$. aureus to sample A with all having similar adhesion force of about 4-5 nN. S. epidermidis RP62a demonstrated the highest overall adhesion forces against the glass in PBS, with increasing adhesion forces with increasing surface roughness of the glass (Figure 4).

Also, S. epidermidis ATCC12228 had a similar pattern of adhesion forces increase with increasing roughness, although not reaching the same values as $S$. epidermidis RP62a; moreover, samples $\mathrm{B}$ and $\mathrm{C}$ had higher adhesive forces compared to their rougher counterparts D and E (Figure 4). Interestingly, the

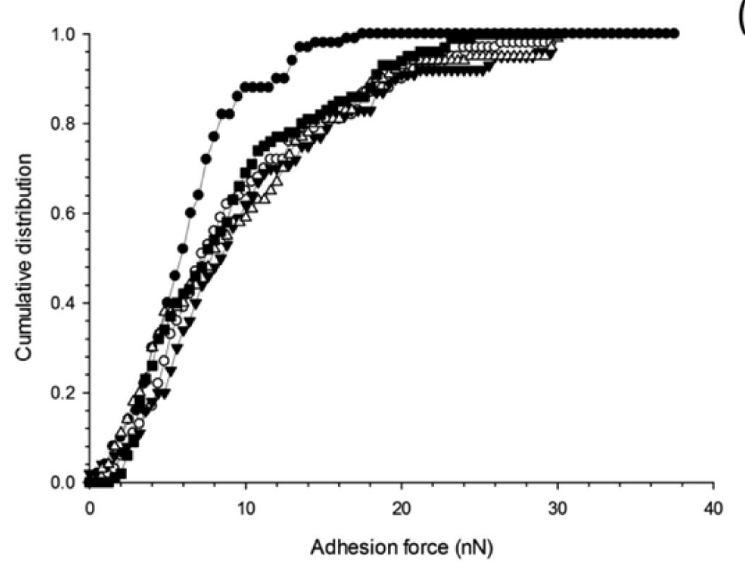

(a)

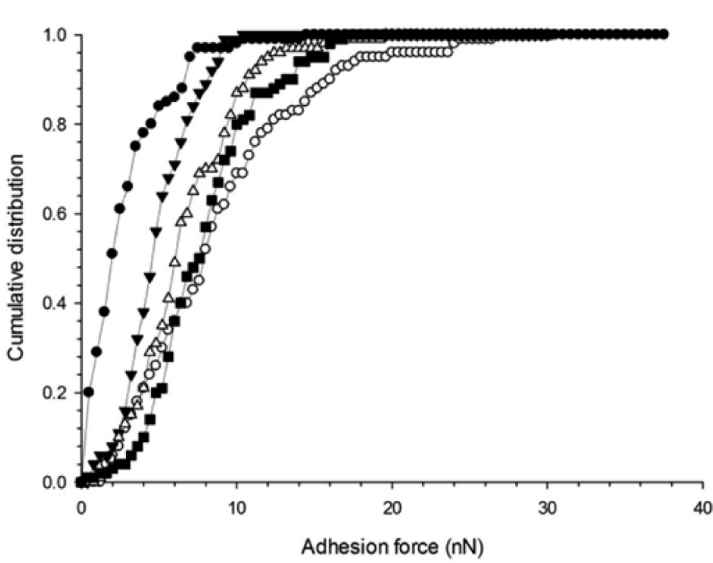

(b)

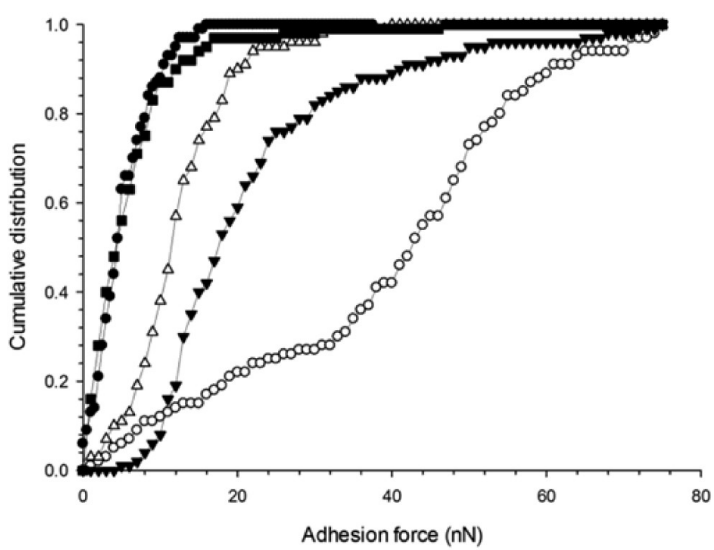

(c)

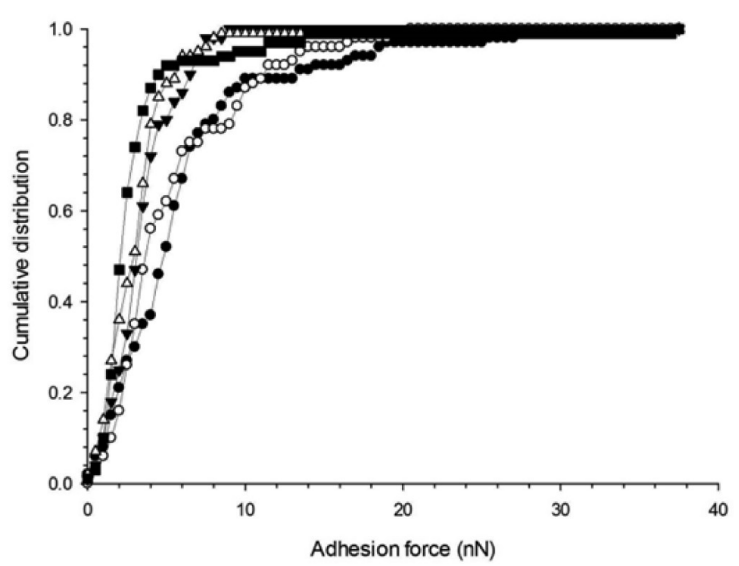

(d)

Figure 4. Cumulative distribution of adhesion force measurements of (a) S. aureus, (b) S. epidermidis ATCC12228, (c) S. epidermidis RP2a, and (d) S. mutans against borosilicate glass in PBS: $(\bullet) \mathrm{A},(\boldsymbol{\square}) \mathrm{B},(\triangle) \mathrm{C},(\boldsymbol{\nabla}) \mathrm{D},(\mathrm{O}) \mathrm{E}$. 


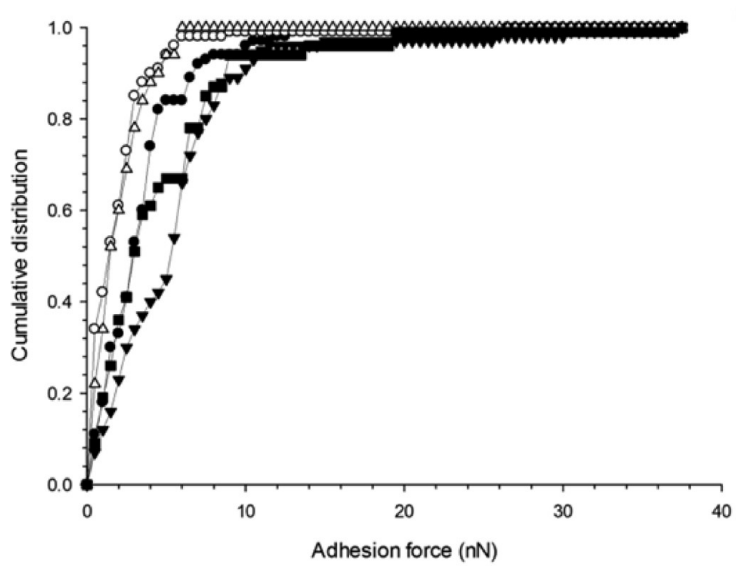

(a)

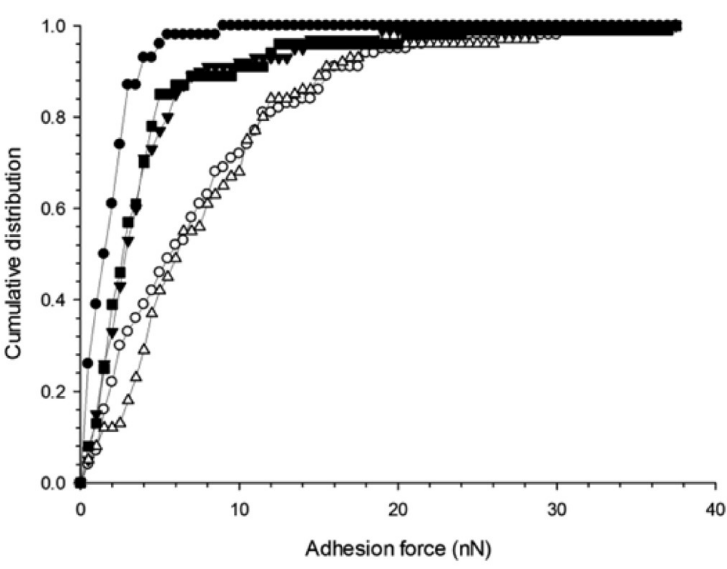

(b)

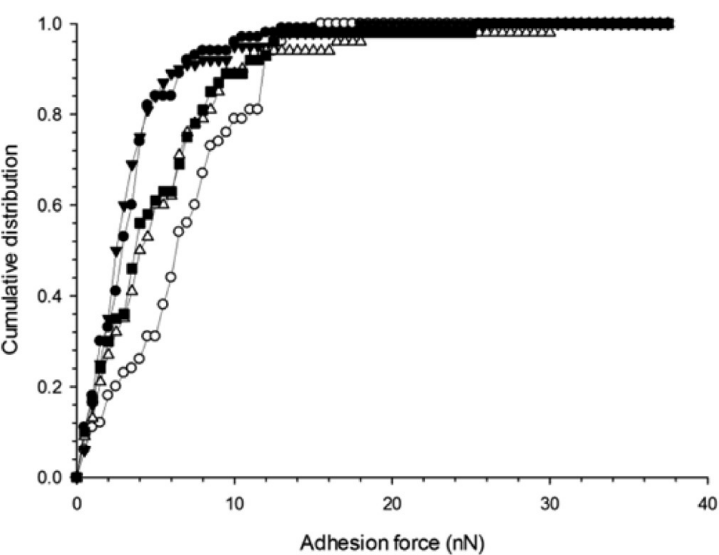

(c)

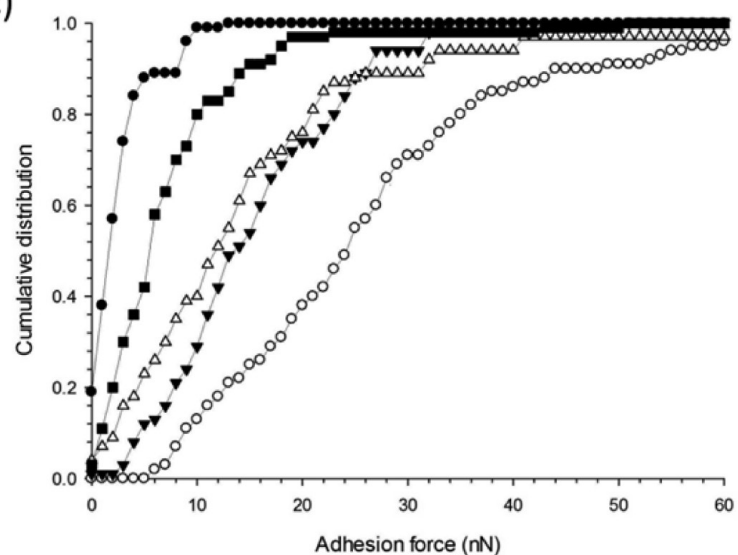

(d)

Figure 5. Cumulative distribution of adhesion force measurements of (a) S. aureus, (b) S. epidermidis ATCC12228, (c) S. epidermidis RP2a, and (d) $S$. mutans against BSA coated borosilicate glass: $(\bullet) \mathrm{A},(\boldsymbol{\square}) \mathrm{B},(\triangle) \mathrm{C},(\boldsymbol{\nabla}) \mathrm{D},(\mathrm{O}) \mathrm{E}$.

adhesion forces measured for $S$. aureus had little change over the range of glass samples regardless of the topography. This was also similar for S. mutans on uncoated samples (Figure 4).

When BSA coating was applied to all glass samples, S. mutans had the greatest adhesion to glass surfaces sample C, D, and $\mathrm{E}$ exhibiting median values of $24 \mathrm{nN}$ (Figure 5). When considering the adhesion of all bacteria with BSA-coated glass, there was not much difference in adhesion forces for $S$. epidermidis RP62a, as forces were much of an extent regardless of the surface of roughness (Figure 5). For S. epidermidis ATCC 12228 , similar results were observed compared to uncoated samples with adhesion forces increasing with increasing roughness; however, samples $\mathrm{C}$ and $\mathrm{E}$ had similar adhesion (Figure 5).

Because of the altered pattern of roughness caused by the BSA coating (Table 1), the possible influence of roughness on adhesion forces was studied through the coefficient of correlation $\left(R^{2}\right)$. The coefficients of correlations increased using surface roughness values obtained from the nanoscale level (scanned areas equal $2 \times 2 \mu \mathrm{m}$ ) (see Supporting Information); furthermore, BSA-coated surfaces demonstrated greater $R^{2}$ values when the actual roughness values (post-BSA coating) were used (see Supporting Information). Interestingly, bacteria that demonstrated higher $R^{2}$ values generally had greater adhesive forces; negative $R^{2}$ values represent lower adhesion forces with rougher surfaces.

\section{DISCUSSION}

We have found that the scanned area of the sample affects the value of the roughness parameter; for example, sample $\mathrm{E}$ had a roughness $\left(R_{\mathrm{a}}\right)$ of $6000 \mathrm{~nm}$ at the macroscale, which decreased at the microscale to $94 \mathrm{~nm}$; this was further reduced at the nanoscale to $62 \mathrm{~nm}$. It appears that roughness parameters are scale dependent; such a phenomenon had also been presented by Perni et al., ${ }^{30,31}$ who determined the roughness of photoactivated materials. This gradual decrease in the overall roughness parameter is important to consider when concerned with the contact area of bacteria and establishing correlation between adhesion forces and roughness. It is noteworthy to mention that the roughness measurements decreased significantly at the nanoscale once a BSA coating was applied; as sample E after BSA coating exhibited an $R_{\mathrm{a}}$ of just $4.2 \mathrm{~nm}$.

Adhesion can be considered as a multifaceted phenomenon, which involves a variety of aspects supplied by both contacting surfaces. Surface topography has been considered $^{33}$ an influential feature governing the extent of adhesion due to variations of the physicochemical nature of the surface. ${ }^{1}$ Bacteria, for example, are known to associate with a wide range of surfaces, natural or synthetic, ${ }^{34}$ mainly as a survival technique. An advantage of adhesion to a surface is the accumulation of nutrients; ${ }^{34-36}$ therefore, attaching to a surface has a positive effect compared to free floating (planktonic bacteria). Remarkably, the environment surrounding the bacteria and the nutrients will have an effect on the structure 
of the adhering microorganisms, ${ }^{36}$ thereby allowing for adaptation and flexibility to survive.

Although this strategy is beneficial for the bacteria in question, it can cause a number of problems in humans, for example, in biomaterials (prosthetic hip and knee joints), as well as vascular grafts and dental implants ${ }^{34,36}$ because bacteria can induce adverse biological responses. Any surface in contact with biological fluids will become coated by a layer of the proteins present in the fluid in a very short period of time; therefore, the subsequent cell adhesion will occur on such coated surface and not on the original substrate. ${ }^{5,10}$ Despite reports of possible antibiofilm formation properties of $\mathrm{BSA},{ }^{37}$ in order to mimic the presence of this layer, BSA is often used because of its biological relevance. ${ }^{16,38,39}$

Generally, in biofilm formation, the bacteria will produce EPS consisting of polysaccharides, proteins, nucleic acids, and lipids; ${ }^{34,40}$ this matrix has a protective function providing mechanical stability. It is this matrix that aids the resistance to antibiotics, ${ }^{5,34}$ affecting the success or failure of implanted medical devices and causing endless, costly problems to the healthcare system as well as the patients. ${ }^{34}$ The main bacteria responsible for failures in implants are S. epidermidis, S. aureus, and $S$. mutans, ${ }^{41-43}$ and for this reason they were selected for this work.

Immobilization of cells on a support for imaging, or to prepare colloidal probes, inevitably induces some changes on the cells. ${ }^{44}$ Protocols are based on different approaches, i.e., entrapment and covalently binding; each method presents advantages and disadvantages. For example, poly(L-lysine) can have antimicrobial activity, but it is simple and suitable for almost any type of cell, while the formation of covalent bonds between the cell and the substrate leads to chemical changes of the cell surface. ${ }^{44}$ As demonstrated by Colville et al., ${ }^{45}$ although cell adhering to poly(L-lysine)-coated substrate presented signs of stress, they remained for the majority viable when immersed in buffer.

Despite the unavoidable variation in the colonization extent of the AFM cantilever, the results showed that the forces of adhesion across three cantilevers colonized, in different occasions, with cells originated from independent cultures, exhibited little variation. This is likely to be the consequence of the fact that adhesion forces measurements are only influenced by the cell present on the tip and not by cells in other location on the cantilever.

Some of the variations in overall adhesion forces can be attributed to the bacterial strain, ${ }^{46,47}$ which are the most common Gram-positive pathogens. The opportunistic pathogen $S$. epidermidis often forms biofilms that enable the bacteria to colonize many medical devices; this is enabled by adhesion factors such as proteins and intracellular adhesin. ${ }^{43}$ However, $S$. epidermidis RP62A is a biofilm producing strain, yet the ATCC 12228 is a nonbiofilm former, ${ }^{43}$ with a gene cluster associated with methicillin-resistant Staphylococcus aureus (MRSA). It has been noted that the difference between $S$. epidermidis and $S$. aureus is the lack of staphylococcal enterotoxins, leukocides, $\alpha$ toxins, protein A, and adherence factors in S. epidermidis, ${ }^{46}$ all of which aid to the survival and virulence of the strain. However, it is important to note that $S$. aureus tends to be more virulent than $S$. epidermidis due to its ability to acquire foreign DNA and enriched immune response. ${ }^{46}$ Most biofilms develop in niches and cracks within implanted devices, but adhesion to the surfaces is also facilitated by the hydrophobic attraction and electrostatic repulsion. ${ }^{48}$
It has been highlighted that initial bacterial adhesion to a surface occurs at defects on the surface such as cracks or grooves; ${ }^{46,48,49}$ this is due to the primitive survival instinct of bacteria as these points provide protection from external factors, such as shear forces. ${ }^{49}$ Also, the transition from reversible to irreversible adhesion is governed by these peaks and troughs on a surface; ${ }^{49}$ therefore, a rougher surface effectively increases the area available for adhesion to take place. However, the role of surface roughness on bacterial adhesion is still without general consensus; a possible reason for this is that, as we have shown in this work, the parameter indicating the roughness of a surface is scale dependent and, consequently, the correlation between surface forces and $R_{\mathrm{a}}$ vary according to the size of the area scanned to calculate the roughness value. Additionally, on BSA-coated surfaces, the value of roughness postcoating is different from the "nominal" value precoating; furthermore, the BSA coating was not a layer of perfectly uniform thickness as the pattern of surface roughness was altered by the protein adsorption. All these phenomena contribute to the uncertainty regarding the effect of surface roughness and bacterial adhesion. Adhesion forces between two contacting bodies can be assumed to be the sum of all individual forces generated by the peaks in contact; hence, the rougher a surface, the higher the adhesion forces as more peaks are in contact. However, when the roughness of a surface is measured on a scale much bigger than the contacting object (in this work a bacteria cell), it is likely that the object could be smaller than the measured peaks and thus no correlation between roughness and adhesion found. On the contrary, when surface roughness is measured on a scale comparable to the contacting object, an increase in roughness could result in higher adhesion forces as the contacting area between the two surfaces increases as shown by Verran et al. ${ }^{50}$ Similar trends were found by Waerhaug, ${ }^{51}$ who demonstrated that roughening subgingival enamel increased the deposition of dental plaque. Also, the adhesion of bacterial cells on titanium and polymer surfaces was promoted by the presence of nanoscale topographical features. ${ }^{52,53}$ Moreover, the importance of the scale of the roughness on cell adhesion was highlighted by Taylor et al., ${ }^{54}$ who found that a small increase in surface roughness resulted in a significant increase in bacterial adhesion while a large increase in surface roughness did not result in a very significant increase in adhesion.

Adhesion forces between bacteria and substrates present both nonspecific and specific contributions, the latter specially when a protein coating is present on the surface; ${ }^{55}$ at the same time, when only nonspecific interactions are present, the adhesion forces are in the range of a few $\mathrm{nN}$, while they are 23 times higher in case of specific interactions; ${ }^{55}$ adhesion could also be subjected to "bond maturation". ${ }^{56}$ We have avoided this phenomenon measuring the adhesion forces without delay. Also, adhesion force between bacteria cells and substrates generally do not follow a normal distribution ${ }^{56-58}$ as in our work.

Our results showed adhesion forces mainly in the range of 4-5 $\mathrm{nN}$ for uncoated glass samples, corroborating previous results $^{55}$ apart from $S$. epidermidis RP62a. Additionally, $S$. mutans on BSA coated had the highest adhesion forces reinforcing the role of this protein in Streptococci adhesion as found previously, despite the BSA not specific contribution to adhesion forces. ${ }^{56}$

Many bacteria possess MSCRAMMs (microbial surface components recognizing adhesive matrix molecules $)^{59}$ that 
allow them specific interactions with fibronectin and not BSA; however, the latter remains a widespread model protein for surface contamination and our work focused on the role of surface roughness on bacterial adhesion forces and how a protein layer on the surface could alter this through changes in surface roughness and surface energy of the substrate. Our results showed that an increase of surface roughness resulted in an increase of adhesion forces mainly for S. epidermidis RP62a on clean glass samples and $S$. mutans on BSA-coated samples; the latter trend was found also for another Streptococci species. $^{56}$

MATS compares the affinity of microbial cells toward varying organic solvents through a partitioning method; ${ }^{29,32}$ the protocol requires four solvents: an electron donor, an electron acceptor, and two nonpolar solvents; chloroform was employed as the electron acceptor, ethyl acetate as the electron donor, as well as hexadecane and decane as the nonpolar solvents. A simple analogy, therefore, to understand the results is that if the cells affinity is greater toward the electron donor solvent than the nonpolar solvent it can be concluded that the cell has electron acceptor characteristics and vice versa; i.e., if the cells affinity is higher for electron acceptor solvents compared to the nonpolar solvents, then the cell is said to have electron donor characteristics. Also, the hydrophobicity of the cell can be measured; the higher the affinity toward the hydrophobic solvents, i.e., hexadecane and decane, the higher the hydrophobicity of the cells surface. S. epidermidis RP62a and ATCC 12228 both have a high affinity for hydrophobic surfaces, whereas $S$. aureus and $S$. mutans have more hydrophilic tendencies. These differences suggest and support the claim that certain characteristics of the cell surface such as fatty acids govern bacteria surface properties. ${ }^{32,60}$

S. epidermidis RP62a had the highest adhesion forces for bare glass and also exhibited an electron donor surfaces as well as the highest affinity toward hydrophobic materials. However, after BSA coating was applied to the glass, S. mutans exhibited the highest adhesion forces; this bacterium demonstrated affinity toward hydrophilic surfaces; these considerations match the results of contact angles of uncoated and BSA coated samples (Table 3) that showed more hydrophilic surfaces after proteins deposition (lower contact angles of water on glass samples after BSA coating).

The glass samples exhibited strong electron donor behavior (high $\gamma^{-}$), while only $S$. aureus presented high affinity toward electron donor solvents. It appears, therefore, that Lewis acidbase interactions did not play a significant role in bacteria adhesion forces to glass substrates; the negligible role of Lewis acid-base interactions in bacterial adhesion was also found in other works. $^{32,61}$

\section{CONCLUSION}

Surface topography has a crucial role in the adhesion phenomena between bacterial cells and substrates in the biofilm formation process. Not only is the bare surface a consideration, but also the fact that proteins will form a conditioning layer on the surface within seconds. This protein layer can effectively mask the real surface and determine the overall adhesion that takes place due to the alterations in the surface chemistry such as hydrophobicity. This investigation, therefore, demonstrates that surface roughness is a critical factor influencing the extent of adhesion forces between glass substrates and bacteria. Furthermore, in virtue of being a scaledependent parameter, better correlations between adhesion forces and surface roughness measurements were obtained when roughness parameters $\left(R_{\mathrm{a}}\right)$ were determined from areas with sizes comparable to bacterial cells.

\section{ASSOCIATED CONTENT}

\section{Supporting Information}

Figures A1-A3 and Tables A1-A5. This material is available free of charge via the Internet at http://pubs.acs.org.

\section{AUTHOR INFORMATION}

\section{Corresponding Author}

*E-mail: prokopovichp@cf.ac.uk (P.P.).

\section{Notes}

The authors declare no competing financial interest.

\section{ACKNOWLEDGMENTS}

The authors acknowledge Arthritis Research UK (ARUK:18461), School of Pharmacy, Cardiff University for a $\mathrm{PhD}$ grant and COST action CM1101 for funding this study.

\section{REFERENCES}

(1) Bos, R.; Van Der Mei, H. C.; Busscher, H. J. Physico-chemistry of Initial Microbial Adhesive Interactions - Its Mechanisms and Methods for Study. FEMS Microbiol. Rev. 1999, 23, 179-230.

(2) Busscher, H. J.; Van Der Mei, H. C. How Do Bacteria Know They Are on a Surface and Regulate Their Response to an Adhering State? PLoS Pathog. 2012, 8, e1002440.

(3) Muszanska, A. K.; Nejadnik, M. R.; Chen, Y.; Van Den Heuvel, E. R.; Busscher, H. J.; Van Der Mei, H. C.; Norde, W. Bacterial Adhesion Forces with Substratum Surfaces and the Susceptibility of Biofilms to Antibiotics. Antimicrob. Agents Chemother. 2012, 56, 4961-4964.

(4) Crawford, R. J.; Webb, H. K.; Truong, V. K.; Hasan, J.; Ivanova, E. P. Surface Topographical Factors Influencing Bacterial Attachment. Adv. Colloid Interface Sci. 2012, 179-182, 142-149.

(5) Percival, S.; Malic, S.; Cruz, H.; Williams, D. Introduction to Biofilms. In Biofilms and Veterinary Medicine; Percival, S., Knottenbelt, D., Cochrane, C., Eds.; Springer: Berlin, 2011.

(6) Van Houdt, R.; Michiels, C. W. Role of Bacterial Cell Surface Structures in Escherichia coli Biofilm Formation. Res. Microbiol. 2005, $156,626-633$.

(7) Hori, K.; Matsumoto, S. Bacterial Adhesion: From Mechanism to Control. Biochem. Eng. J. 2010, 48, 424-434.

(8) Cateau, E.; Berjeaud, J.-M.; Rodier, M.-H.; Imbert, C. Fungal Biofilm Inhibition By a Component Naturally Produced by Candida Albicans Yeasts Growing as a Biofilm. Int. J. Antimicrob. Agents 2008, $31,166-170$

(9) Piñeres, J.; Barraza, J. Energy Barrier of Aggregates Coal ParticleBubble Through the Extended DLVO Theory. Int. J. Mineral Proc. 2011, 100, 14-20.

(10) Walker, J. T.; Marsh, P. D. A Review of Biofilms and their Role in Microbial Contamination of Dental Unit Water Systems (DUWS). Int. Biodeterior. Biodegrad. 2004, 54, 87-98.

(11) Jaglic, Z.; Červinková, D.; Vlková, H.; Michu, E.; Kunová, G.; Babák, V. Bacterial Biofilms Resist Oxidising Agents due to the Presence of Organic Matter. Czech J. Food Sci. 2012, 30, 178-187.

(12) Shi, X.; Zhu, X. Biofilm Formation and Food Safety in Food Industries. Trends Food Sci. Technol. 2009, 20, 407-413.

(13) Poulsen, L. V. Microbial Biofilm in Food Processing. Food Sci. Technol. 1999, 32, 321-326.

(14) Rochex, A.; Lebeault, J. M. Effects of Nutrients on Biofilm Formation and Detachment of a Pseudomonas putida Strain Isolated From a Paper Machine. Water Res. 2007, 41, 2885-2892.

(15) Hu, Y.; Ulstrup, J.; Zhang, J.; Molin, S.; Dupres, V. Adhesive Properties of Staphylococcus epidermidis Probed by Atomic Force Microscopy. Phys. Chem. Chem. Phys. 2011, 13, 9995-10003. 
(16) Boks, N. P.; Busscher, H. J.; Van Der Mei, H. C.; Norde, W. Bond-Strengthening in Staphylococcal Adhesion to Hydrophilic and Hydrophobic Surfaces Using Atomic Force Microscopy. Langmuir 2008, 24, 12990-12994.

(17) Tsang, C. S. P.; Ng, H.; Mcmillan, A. S. Antifungal Susceptibility of Candida albicans Biofilms on Titanium Discs with Different Surface Roughness. Clin. Oral Invest. 2007, 11, 361-368.

(18) Percival, S. L.; Knapp, J. S.; Wales, D. S.; Edyvean, R. G. J. The Effect of Turbulent Flow and Surface Roughness on Biofilm Formation in Drinking Water. J. Ind. Microbiol. Biotechnol. 1999, 22, 152-159.

(19) Fröjd, V.; Linderbäck, P.; Wennerberg, A.; Chávez De Paz, L.; Svensäter, G.; Davies, J. Effect of Nanoporous $\mathrm{TiO}_{2}$ Coating and Anodized $\mathrm{Ca}^{2+}$ Modification of Titanium Surfaces on Early Microbial Biofilm Formation. BMC Oral Health 2011, 11, 1-9.

(20) Cao, T.; Tang, H.; Liang, X.; Wang, A.; Auner, G. W.; Salley, S. O.; Ng, K. Y. S. Nanoscale Investigation on Adhesion of E. coli to Surface Modified Silicone Using Atomic Force Microscopy. Biotechnol. Bioeng. 2006, 94, 167-176.

(21) Busscher, H.; Weerkamp, A. Specific and Nonspecific Interactions in Bacterial Adhesion to Solid Substrata. FEMS Microbiol. Rev. 1987, 46 (2), 165-173.

(22) Bendersky, M.; Davis, J. M. DLVO Interaction of Colloidal Particles with Topographically and Chemically Heterogeneous Surfaces. J. Colloid Interface Sci. 2011, 353, 87-97.

(23) Bohinc, K.; Dražić, G.; Fink, R.; Oder, M.; Jevšnik, M.; Nipič, D.; Godič Torkar, K.; Raspor, P. Available surface dictates microbial adhesion capacity. Int. J. Adhes. Adhes. 2014, 50 (1), 265-272.

(24) Homola, A. M.; Israelachvili, J. N.; Mcguiggan, P. M.; Gee, M. L. Fundamental Experimental Studies in Tribology: The Transition From "Interfacial" Friction of Undamaged Molecularly Smooth Surfaces to "Normal" Friction with Wear. Wear 1990, 136, 65-83.

(25) Blau, P. J. Scale Effects in Steady-State Friction. Tribol. Trans. 1991, 34, 335-342.

(26) Allen, S.; Davies, M. C.; Roberts, C. J.; Tendler, S. J. B.; Williams, P. M. Atomic Force Microscopy in Analytical Biotechnology. Trends Biotechnol. 1997, 15, 101-105.

(27) Mistry, S.; Kundu, D.; Datta, S.; Basu, D. Comparison of Bioactive Glass Coated and Hydroxyapatite Coated Titanium Dental Implants in the Human Jaw Bone. Aust. Dent. J. 2011, 56, 68-75.

(28) Sader, J. E.; Larson, I.; Mulvaney, P.; White, L. R. Method for the Calibration of Atomic Force Microscope Cantilevers. Rev. Sci. Instrum. 1995, 66, 3789-3798.

(29) Bellon-Fontaine, M. N.; Rault, J.; Van Oss, C. J. Microbial adhesion to solvents: a novel method to determine the electrondonor/electron acceptor or Lewis acid-base properties of microbial cells. Colloids Surf., B 1996, 7, 47-53.

(30) Perni, S.; Prokopovich, P.; Piccirillo, C.; Pratten, J. R.; Parkin, I. P.; Wilson, M. Toluidine Blue-Containing Polymers Exhibit Bactericidal Activity When Irradiated with Red Light. J. Mater. Chem. 2009, 19 (17), 2715-2723.

(31) Perni, S.; Piccirillo, C.; Parkin, I. P.; Prokopovich, P.; Chrzanowski, W.; Parkin, I. P.; Wilson, M. The Antimicrobial Properties of Light-activated Polymers Containing Methylene Blue and Gold Nanoparticles. Biomaterials 2009, 30 (1), 89-93.

(32) Prokopovich, P.; Perni, S. An Investigation of Microbial Adhesion to Natural and Synthetic Polysaccharide-Based Films and its Relationship with the Surface Energy Components. J. Mater. Sci.: Mater. Med. 2009, 20, 195-202.

(33) Prokopovich, P.; Starov, V. Adhesion Models: From Single to Multiple Asperity Contacts. Adv. Colloid Interface Sci. 2011, 168, 210222.

(34) Busscher, H. J.; Van Der Mei, R. B. H. C. Initial Microbial Adhesion is a Determinant for the Strength of Biofilm Adhesion. FEMS Microbiol Lett. 1995, 128, 229-234.

(35) Fletcher, M. Bacterial Biofilms and Biofouling. Curr. Opin. Biotechnol. 1994, 5, 302-306.
(36) Hall-Stoodley, L.; Costerton, J. W.; Stoodley, P. Bacterial Biofilms: From the Natural Environment to Infectious Diseases. Nat. Rev. Microbiol. 2004, 2, 95-108.

(37) Huang, T. T.; Sturgis, J.; Gomez, R.; Geng, T.; Bashir, R.; Bhunia, A. K.; Robinson, J. P.; Ladisch, M. R. Composite Surface for Blocking Bacterial Adsorption on Protein Biochips. Biotechnol. Bioeng. 2003, 81, 618-624.

(38) Xu, C. P.; Boks, N. P.; de Vries, J.; Kaper, H. J.; Norde, W.; Busscher, H. J.; van der Mei, H. C. Staphylococcus aureus-Fibronectin Interactions with and without Fibronectin-Binding Proteins and Their Role in Adhesion and Desorption. Appl. Environ. Microbiol. 2008, 74, $7522-7528$.

(39) Xu, L. C.; Logan, B. E. Interaction Forces between Colloids and Protein-Coated Surfaces Measured Using an Atomic Force Microscope. Environ. Sci. Technol. 2005, 39 (10), 3592-3600.

(40) Flemming, H. C.; Wingender, J. The Biofilm Matrix. Nat. Rev. Microbiol. 2010, 8, 623-633.

(41) Valour, F.; Trouillet-Assant, S.; Rasigade, J.-P.; Lustig, S.; Chanard, E.; Meugnier, H.; Tigaud, S.; Vandenesch, F. O.; Etienne, J.; Ferry, T.; Laurent, F. Staphylococcus epidermidis in Orthopedic Device Infections: The Role of Bacterial Internalization in Human Osteoblasts and Biofilm Formation. PLoS Pathog. 2013, 8, 1-11.

(42) Widmer, A. F. New Developments in Diagnosis and Treatment of Infection in Orthopedic Implants. Clin. Infect. Dis. 2001, 33, S94S106.

(43) Rosenthal, M. E.; Dever, L. L.; Moucha, C. S.; Chavda, K. D.; Otto, M.; Kreiswirth, B. N. Molecular Characterization of an Early Invasive Staphylococcus epidermidis Prosthetic Joint Infection. Microb. Drug Resist. 2011, 17, 345-350.

(44) Kuyukina, M. S.; Korshunova, I. O.; Rubtsova, E. V.; Ivshina, I. B. Methods of Microorganism Immobilization for Dynamic AtomicForce Studies (Review). Appl. Biochem. Microbiol. 2014, 50, 1-9.

(45) Colville, K.; Tompkins, N.; Rutenberg, A. D. Jericho, M.H. Effects of Poly(L-lysine) Substrates on Attached Escherichia coli Bacteria. Langmuir 2010, 26, 2639-2644.

(46) Fey, P. D.; Olson, M. E. Current Concepts in Biofilm Formation of Staphylococcus epidermidis. Fut. Microbiol. 2010, 5, 917-933.

(47) Fredheim, E. G. A.; Klingenberg, C.; Rohde, H.; Frankenberger, S.; Gaustad, P.; Flægstad, T.; Sollid, J. E. Biofilm Formation by Staphylococcus Haemolyticus. J. Clin. Microbiol. 2009, 47, 1172-1180.

(48) Loosdrecht, M. M.; Norde, W.; Lyklema, J.; Zehnder, A. B. Hydrophobic and Electrostatic Parameters in Bacterial Adhesion. Aquat. Sci. 1990, 52, 103-114.

(49) Gharechahi, M.; Moosavi, H.; Forghani, M. Effect of Surface Roughness and Materials Composition on Biofilm Formation. J. Biomater. Nanobiotechnol. 2012, 230, 541-546.

(50) Verran, J.; Packer, A.; Kelly, P. J.; Whitehead, K. A. Use of the Atomic Force Microscope to determine the Strength of Bacterial Attachment to Grooved Surface Features. In Surface and Interfacial Aspects of Cell Adhesion; Carré, A., Mittal, K. L., Eds.; VSP: Leiden, The Netherlands, 2010.

(51) Waerhaug, J. Effect of Rough Surfaces Upon Gingival Tissue. J. Dent. Res. 1956, 35, 323-325.

(52) Truong, V. K.; Lapovok, R.; Estrin, Y. S.; Rundell, S.; Wang, J. Y.; Fluke, C. J.; Crawford, R. J.; Ivanova, E. P. The Influence of NanoScale Surface Roughness on Bacterial Adhesion to Ultrafine-Grained Titanium. Biomaterials 2010, 31, 3674-3683.

(53) Bakker, D. P.; Busscher, H. J.; Van Zanten, J.; De Vries, J.; Klijnstra, J. W.; Van Der Mei, H. C. Multiple Linear Regression Analysis of Bacterial Deposition to Polyurethane Coatings after Conditioning Film Formation in the Marine Environment. Microbiology 2004, 150, 1779-1784.

(54) Taylor, R. L.; Verran, J.; Lees, G. C.; Ward, A. J. The Influence of Substratum Topography on Bacterial Adhesion to Polymethyl Methacrylate. J. Mater. Sci.: Mater. Med. 1998, 9, 17-22.

(55) Busscher, H. J.; Norde, W.; van der Mei, H. C. Specific Molecular Recognition and Interaction Forces Nonspecific Contributions to Bacterial. Appl. Environ. Microbiol. 2008, 74, 2559-2564. 
(56) Mei, L.; Busscher, H. J.; van der Mei, H. C.; Ren, Y. Influence of Surface Roughness on Streptococcal Adhesion Forces to Composite Resins. Dent. Mater. 2011, 27, 770-778.

(57) Van der Mei, H. C.; De Vries, J.; Busscher, H. J. Weibull Analyses of Bacterial Interaction Forces Measured Using AFM. Colloids Surf., B 2010, 78, 372-375.

(58) Mei, L.; Busscher, H. J.; Van der Mei, H. C.; Chen, Y.; De Vries, J.; Ren, Y. Oral Bacterial Adhesion Forces to Biomaterial Surfaces Constituting the Bracket-Adhesive-Enamel Junction in Orthodontic Treatment. Eur. J. Oral Sci. 2009, 117, 419-426.

(59) Perkins, S.; Walsh, E. J.; Deivanayagam, C. C.; Narayana, S. V.; Foster, T. J.; Höök, M. Structural Organization of the FibrinogenBinding Region of the Clumping Factor B MSCRAMM of Staphylococcus aureus. J. Biol. Chem. 2001, 276, 44721-44728.

(60) Mastronicolis, S. K.; Berberi, A.; Diakogiannis, I.; Petrova, E.; Kiaki, I.; Baltzi, T.; Xenikakis, P. Alteration of the Phospho- or Neutral Lipid Content and Fatty Acid Composition in Listeria monocytogenes Due to Acid Adaptation Mechanisms for Hydrochloric, Acetic and Lactic Acids at $\mathrm{pH} 5.5$ or Benzoic Acid at Neutral pH. Antonie Van Leeuwenhoek 2010, 98, 307-316.

(61) Perni, S.; Callard Preedy, E.; Prokopovich, P. Success and Failure of Colloidal Approached in Bacterial Adhesion. Adv. Colloid Interface Sci. 2014, 206, 265-274. 


\title{
Surface Roughness Mediated Adhesion Forces
}

\section{between Borosilicate Glass and Gram-Positive}

\section{Bacteria-Supporting info}

\author{
Emily Preedy ${ }^{1}$, Stefano Perni ${ }^{1,3}$, Damijan Nipic ${ }^{4}$, Klemen Bohinc ${ }^{5}$ and Polina \\ Prokopovich ${ }^{1,2,3, *}$
}

${ }^{1}$ Cardiff School of Pharmacy and Pharmaceutical Science, Cardiff University, Cardiff, UK

${ }^{2}$ Cardiff School of Engineering, Cardiff University, Cardiff, Cardiff, UK

${ }^{3}$ Department of Biological Engineering, Massachusetts Institute of Technology, Cambridge, MA, USA

${ }^{4}$ Department of Biology, Biotechnical Faculty, University of Ljubljana, Ljubljana, Slovenia ${ }^{5}$ Faculty of Health Science, University of Ljubljana, Ljubljana, Slovenia 

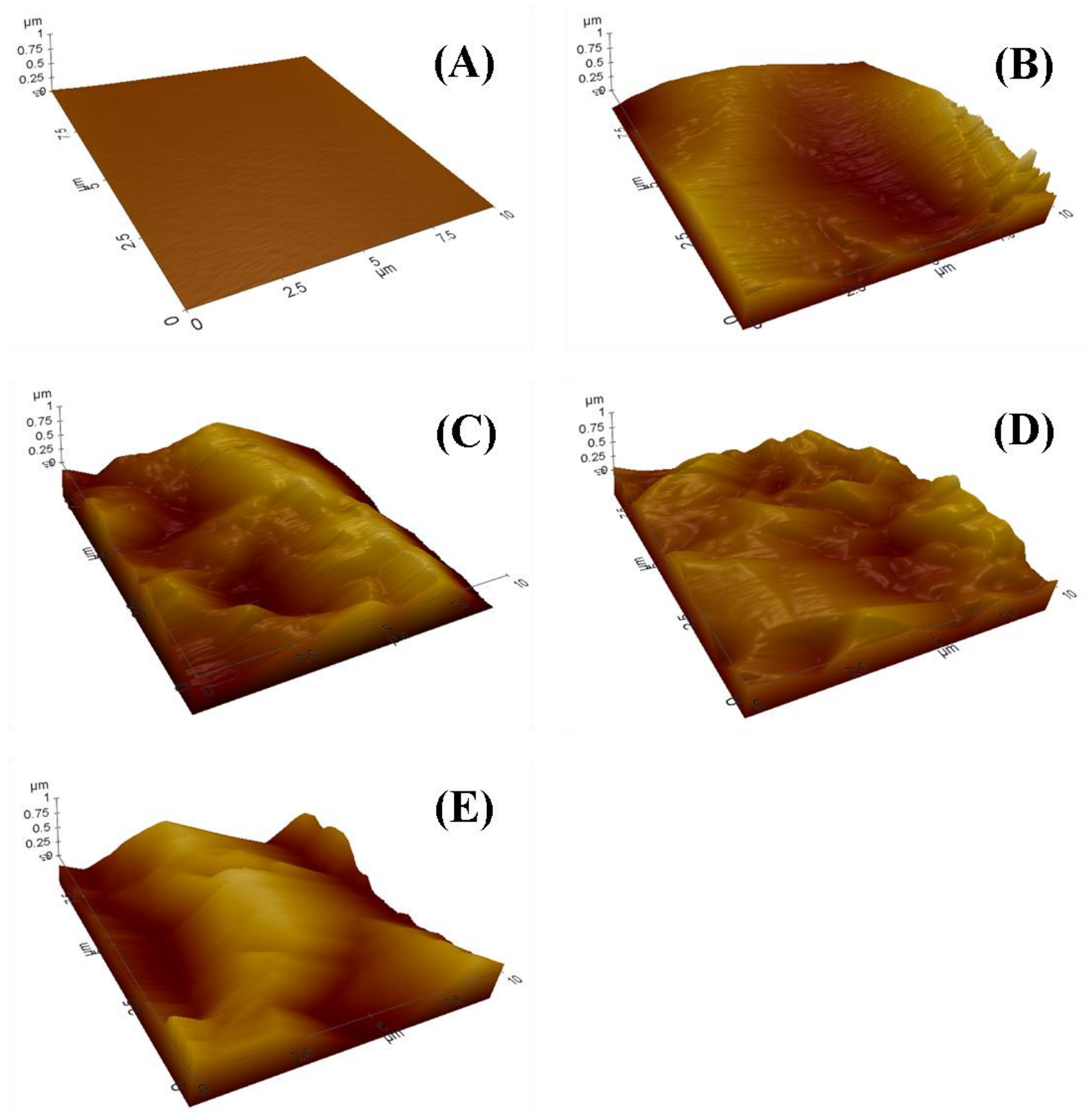

Figure A1. Microscale images of all glass samples A-E, coated with BSA 

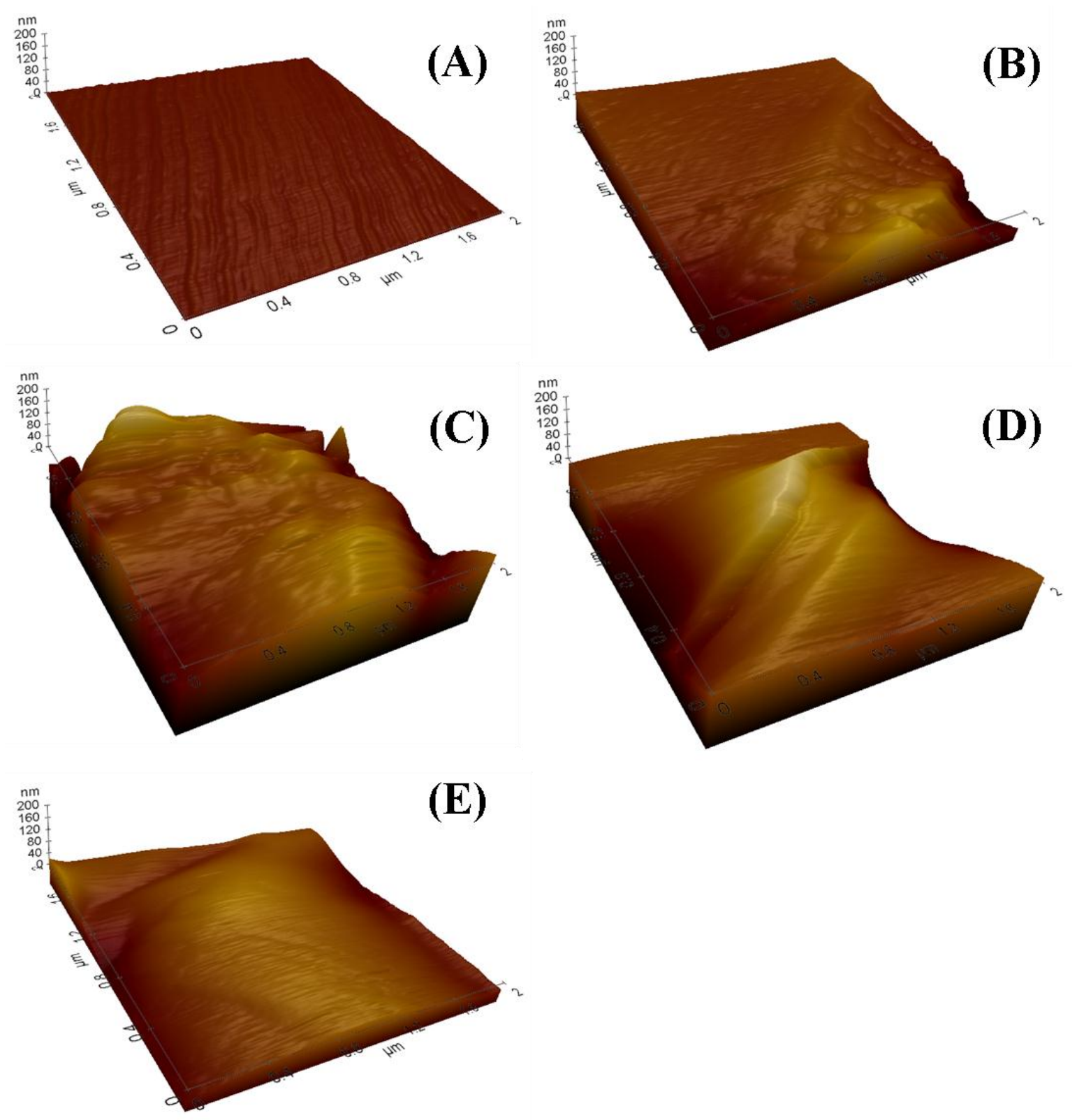

Figure A2. Nanoscale images of all bare glass samples A-E 

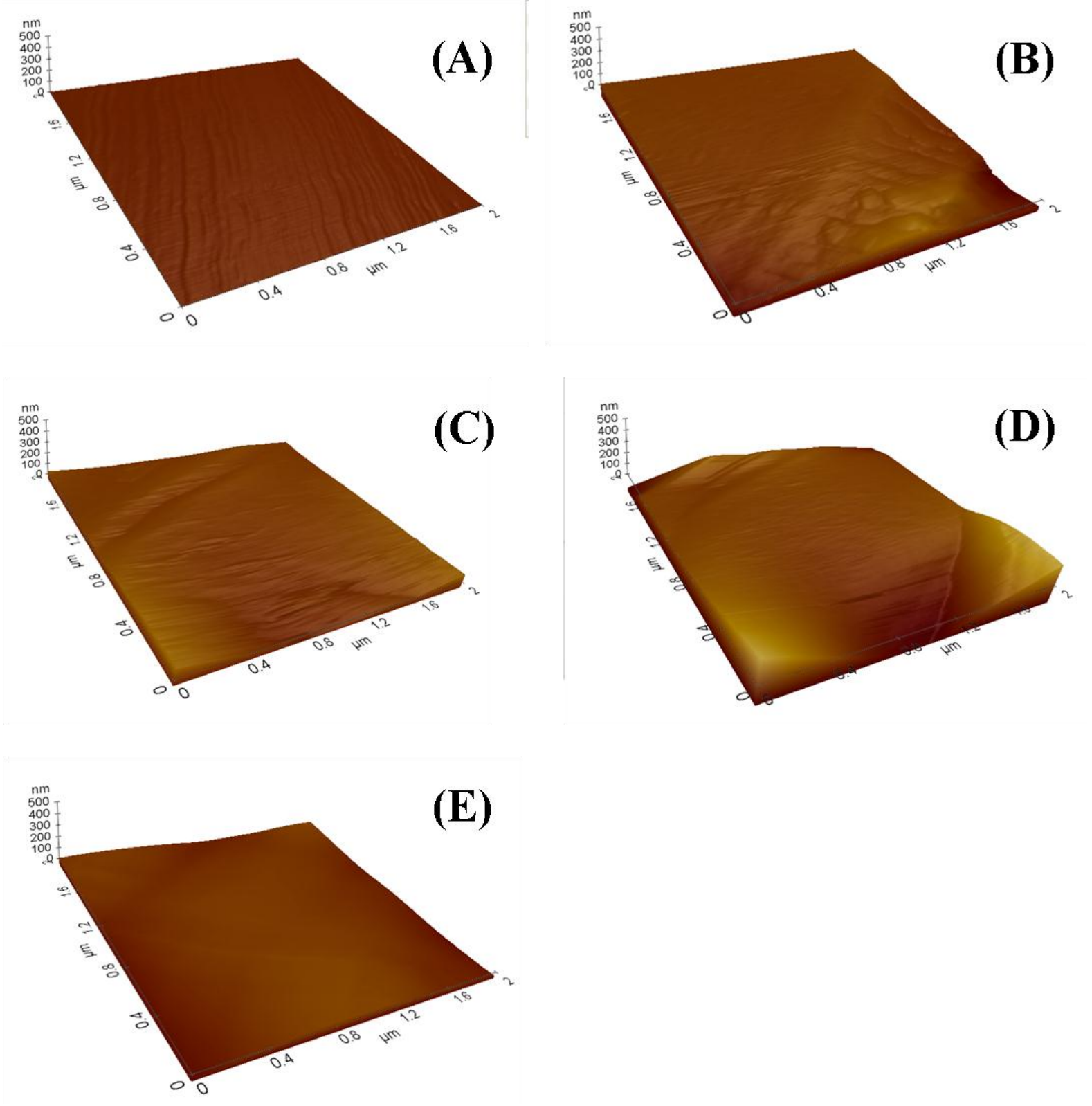

Figure A3. Nanoscale images of all glass samples A-E coated with BSA 
Table A1. Median values of bacterial adhesion force $(\mathrm{nN})$ against clean glass samples.

\begin{tabular}{|l|l|l|l|l|}
\hline & $\begin{array}{l}\text { S. epidermidis } \\
\text { RP62a }\end{array}$ & $\begin{array}{l}\text { S. epidermidis } \\
\text { ATCC12228 }\end{array}$ & S. aureus & S. mutans \\
\hline A & 4.25 & 2.0 & 5.75 & 4.75 \\
\hline B & 4.2 & 7.6 & 9.25 & 2.5 \\
\hline C & 11.5 & 6.0 & 9.75 & 3.0 \\
\hline D & 17.5 & 4.6 & 10.5 & 3.2 \\
\hline E & 42 & 7.8 & 9.0 & 3.75 \\
\hline
\end{tabular}

Table A2. Median values of bacterial adhesion force $(\mathrm{nN})$ against BSA-coated glass samples.

\begin{tabular}{|l|l|l|l|l|}
\hline & $\begin{array}{l}\text { S. epidermidis } \\
\text { RP62a }\end{array}$ & $\begin{array}{l}\text { S. epidermidis } \\
\text { ATCC12228 }\end{array}$ & S. aureus & S. mutans \\
\hline A & 2.75 & 1.5 & 2.75 & 0.75 \\
\hline B & 3.25 & 2.75 & 3.0 & 5.5 \\
\hline C & 4.0 & 6.0 & 1.5 & 12 \\
\hline D & 2.5 & 2.75 & 5.25 & 14 \\
\hline E & 6.25 & 5.5 & 1.25 & 24 \\
\hline
\end{tabular}


Table A3. Coefficients of correlation $\left(R^{2}\right)$ for the bacteria adhesion forces in PBS against values of surface roughness obtained from varying scanned areas.

\begin{tabular}{|l|l|l|l|l|}
\hline & $\begin{array}{l}\text { S. epidermidis } \\
\text { RP62a }\end{array}$ & $\begin{array}{l}\text { S. epidermidis } \\
\text { ATCC12228 }\end{array}$ & S. aureus & S. mutans \\
\hline correlation macro & 0.995394 & 0.617702 & 0.446555 & -0.01364 \\
\hline correlation micro & 0.98856 & 0.520074 & 0.387439 & 0.077206 \\
\hline correlation nano & 0.801811 & 0.701453 & 0.777379 & -0.35493 \\
\hline
\end{tabular}

Table A4. Coefficients of correlation for the bacteria adhesion forces with BSA coated surface against values of surface roughness obtained from varying scanned areas before BSA deposition.

\begin{tabular}{|l|l|l|l|l|}
\hline & $\begin{array}{l}\text { S. epidermidis } \\
\text { RP62a }\end{array}$ & $\begin{array}{l}\text { S. epidermidis } \\
\text { ATCC12228 }\end{array}$ & S. aureus & S. mutans \\
\hline correlation macro & 0.755864 & 0.535618 & -0.22737 & 0.941964 \\
\hline correlation micro & 0.688002 & 0.516285 & -0.17544 & 0.935404 \\
\hline correlation nano & 0.458064 & 0.618088 & 0.029452 & 0.941385 \\
\hline
\end{tabular}

Table A5. Coefficients of correlation for the bacteria adhesion forces on BSA coated surface against values of surface roughness obtained from varying scanned areas after BSA deposition.

\begin{tabular}{|l|l|l|l|l|}
\hline & $\begin{array}{l}\text { S. epidermidis } \\
\text { RP62a }\end{array}$ & $\begin{array}{l}\text { S. epidermidis } \\
\text { ATCC12228 }\end{array}$ & S. aureus & S. mutans \\
\hline correlation micro & 0.626158 & 0.707773 & -0.1518 & 0.98173 \\
\hline correlation nano & 0.611871 & 0.964164 & -0.5494 & 0.722775 \\
\hline
\end{tabular}

